\title{
LAS “NOCHES”: UN SUBGÉNERO NOVELÍSTICO EN PERSPECTIVA COMPARADA ${ }^{1}$
}

\author{
Mechthild AlBert \\ Rheinische Friedrich-Wilhelms-Universität Bonn \\ malbert@uni-bonn.de
}

\section{INTRODUCCIÓN}

on el creciente éxito de la novela corta en España a principios del siglo
XVII, se va a instaurar un determinado tipo de título estereotipado, como
observa Montero Reguera:

Esas colecciones repiten además títulos parecidos o muy semejantes, que acaban convirtiéndose en una suerte de reclamo publicitario que los escritores y editores saben aprovechar muy bien: un título breve que, generalmente, atiende a dos coordenadas: una espacial (jardín, cigarral, Madrid, Toledo, Valencia, academia, casas, etc.) y otra temporal (noches, días, horas, etc.); en ocasiones se añaden variantes que suelen incidir en el aspecto moral y de entretenimiento (honesto, escarmiento, agradable, gustoso, apacible) y genérico (novela): Días de jardín, Tardes entretenidas, Jornadas alegres, Tiempo de regocijo y carnestolendas en Madrid, Noches de placer, Fiestas del jardín, Huerta de Valencia, Noches de invierno, Novelas ejemplares y prodigiosas, Academias del jardín, Las clavellinas de recreación, Cigarrales de Toledo, Deleitar aprovechando, etc. (Montero Reguera 2006: 167).

A este respecto, Alonso de Castillo Solórzano (1584-¿1648?), uno de los más prolíficos cultivadores del género, proporciona ejemplos como Tardes entretenidas (1625), Jornadas alegres (1626) o Noches de placer (1631). Tales fórmulas, que indican, además, el cronotopo particular de la novelística², están «directamente calcad[as] del título italiano de Piacevoli notti de Straparola», como señala

\footnotetext{
1 Este trabajo se inscribe en el marco del Proyecto I+D+i del MINECO La novela corta del siglo XVII (y II) (FFI2013-41264-P) y del proyecto financiado por la DFG Los saberes del ocioso Muße, Geselligkeit und Wissen im Siglo de Oro.

2 Véase Albert (2013).
} 
Cayuela (2000: 452). Esta colección de novelas cortas, publicada en dos tomos en 1550 y 1553 y destinada a ganar enorme influencia en Europa, fue traducida al castellano por Francisco Truchado, «vecino de Baeza», bajo el título Honesto y agradable entretenimiento de damas y galanes, igualmente en dos partes, en 1580 y $1581^{3}$. En el presente artículo se propone un acercamiento comparado a estas dos colecciones con idéntico título -Piacevoli notti y Noches de placer- para analizar las dimensiones significativas de la «noche», teniendo en cuenta tanto el marco narrativo como las narraciones intercaladas, con vistas a averiguar en qué medida esta denominación posee niveles de significado que van más allá del simple «reclamo publicitario» y que contribuyen a constituir un subgénero propio, el de las «Noches».

Evidentemente, la recurrencia y continuidad de los títulos mencionados indica que la novelística occidental moderna —inaugurada por Boccaccio— constituye, por una parte, un género literario regido por ciertas normas y que se refiere, por otra parte, a determinada práctica cultural. A saber: la sociabilidad entre cortesana y urbana que queda reflejada en el marco ${ }^{4}$. Esta complejidad se manifiesta, por ejemplo, en la polisemia del término "sérée» que sirve de título a la miscelánea (1584/1608) del autor-librero-impresor francés Guillaume Bouchet (1514-1594)5. Se trata de la obra de un humanista modesto que hace referencia a Platón y a Catón para sus «Noches», como cita y comenta Ménager (2005: 229-230):

'Nous faisions nos banquets bien avant en la nuict, imitant Socrate et Agathon, qui demeurerent toute la nuict au banquet de Platon'. [...] Et si le banquet se prolonge, ce n'est pas pour profiter de la 'licence' introduite par la nuit. C'est le 'plaisir de la société et compagnie des honnestes, savants et vertueux' qui explique ces longues soirées. Et puis, pourquoi en aurait-on honte, puisque l'austère Caton lui-même avoue dans un dialogue de Cicéron qu'il aime passer une partie de la nuit avec ses amis?

Aparte de tales referencias eruditas, la costumbre de contar anécdotas chistosas e historias inverosímiles durante las largas noches de invierno es evocada por Maxime Chevalier, quien se apoya en los testimonios de Cervantes y Lope de Vega a propósito de las «consejas o cuentos de viejas [...] con que se entretienen al fuego las dilatadas noches del invierno», o sea, «cuentos / de viejas, para

3 Para más detalles respecto a la traducción y edición de las Piacevoli notti en España, véase González Ramírez (2011: 1221-1243, 1225-1227, 1233-1235).

4 Para la relevancia cultural y literaria de la sociabilidad en la España áurea véase Albert (ed.) (2013).

5 En esta obra, el término «sérée» abarca tres acepciones, representativas del género de las «noches» o «tardes»: «causeries accompagnant et prolongeant le souper, partie de la veillée qui leur est consacrée», «ensemble des devisants, 'société conteuse'», y «unité textuelle composite, prétendue relation des propos tenus au cours d'une même soirée; au pluriel, titre donné à une collection de ces entretiens» (Renaud 2000: 71-87, 75). Véase también Jeanneret (1987: 178) y Janier (2006). 
la lumbre, / las noches de los inviernos» (Chevalier 1975: 15-16). En el ámbito cortesano y urbano también suelen contarse facecias y cuentos en las reuniones entretenidas de tarde o de noche, tal como se expone, por ejemplo, en El Cortesano de Castiglione. Esta práctica cultural de tipo oral se plasma en el marco y la estructura de las colecciones de novela corta, como explica Cayuela a propósito de las Tardes entretenidas de Castillo Solórzano:

la presencia como titulillo el de tarde primera, segunda, tercera, etc. revela la concepción global de la obra: las unidades narrativas no son las diferentes novelas contenidas en el libro. Lo que puede aparecer como un detalle es en realidad un elemento muy significativo de la concepción arquitectónica del libro, como una sucesión de Tardes, unidades temporales de entretenimiento, a su vez constituidas por unidades textuales destinadas a divertir: novelas, poesías, enigmas. Además observamos que la Tarde forma una unidad tipográfica, no hay salto de página entre novela y enigmas que rematan la tarde, como tampoco lo hay cuando empieza una novela (Cayuela 2000: 452-453).

Las «Noches» como título y concepto genérico ${ }^{6}$ se encuentran explícita e implícitamente en obras como Navidades de Madrid y noches entretenidas (1663) de Mariana de Carvajal y Saavedra, Sala de recreación (1649) de Castillo Solórzano, así como en las Noches de invierno (1609) de Antonio de Eslava. Además de las Piacevoli notti de Straparola, cuya influencia resulta dudosa en este caso, el mismo título de Noches de invierno «nos lleva [...] a la tradición de las compilaciones eruditas y misceláneas al estilo de las Noches Áticas» (Barella Vigal 1985: 546). Si bien es cierto que Eslava no menciona expresamente a Aulo Gelio, la referencia intertextual a las «noches» de este es señal suficiente cuando expone en el «Prólogo al discreto lector»: «como mis Diálogos son de noches, [...] salen a escuras $[\ldots]$ y amanecen a las puertas de tu entendimiento para que los ampares» (Eslava 2013: 48). Aquí nos encontramos con una lectura metafórica, desconocida por los novellieri, que se refiere a la formación intelectual. De hecho, el núcleo semántico de la noche, la vigilia y la elucubración constituye, desde Pedro Mexía (Proemio a la Silva de varia lección), un claro guiño a las Noches áticas, adquiriendo «verdadero carácter metaliterario» (García Jurado 2012: 59) ${ }^{7}$ En este contexto resultan reveladores otros paratextos, como el soneto de Miguel de Hureta en alabanza al autor de las Noches de invierno: «"Eslava es el que da a las noches lumbre / y gusto al alma, y entretiene al tiempo / con coloquios discretos y curiosos”. / Esto canta la fama de su cumbre, / y en ver de noches tanto pasatiempo /

$6 \quad$ Mención aparte merecen el diálogo Corte de aldea y noches de invierno (1619), del portugués Francisco Rodrigues Lobo, así como la colección de poemas Noches claras (1624), de Manuel de Faria e Sousa.

7 Véase Albert (2014).

Edad de Oro, XXXIII (2014), pp. 365-381, ISSN: 0212-0429 
los días andan dellas envidiosos» (Eslava 2013: 54). Más explícito es el soneto que Juan de Eslava, «racionero de la catedral de Valladolid», dedica a su hermano Antonio: «Que ya en las noches por su ausencia frígidas / Eslava da más luz que la Latónica / con sus Noches escritas en diálogos. / Y en trágicas historias y muy rígidas / con lengua aristotélica y platónica / imita a otro Gelio en sus Catálogos» (Eslava 2013: 58) ${ }^{8}$. Incluso Tirso de Molina se refiere a las Noches Áticas cuando comenta, en un pasaje de sus Cigarrales de Toledo:

Las tardes se les hacían cortas, ya por las apacibles conversaciones en que, sirviendo los ingenios diferentes platos al entendimiento sustentaban las almas, ya en juegos pacíficos, estafermos y carreras [...]; las noches en saraos artificiosos, motes más agudos que satíricos, y disputas tan curiosas como claras que pudieran dar envidia a las Noches áticas de Aulo Gelio y Días saturnales de Macrobio (Molina 1996: 231-232).

Al considerar las Piacevoli notti como fuente de las Noches de placer y las Noches áticas como modelo de las Noches de invierno, podemos observar cómo las noches eruditas de Gelio y las noches placenteras de Straparola confluyen, pues, en el género extremamente maleable y popular de la novela corta, creando el subgénero de las «Noches».

Finalmente, a la hora de tomar en consideración la carga narrativa de la noche en cuanto motivo literario, conviene recordar que esta forma parte de las «estructuras antropológicas del imaginario», según Durand, como elemento constitutivo de la dicotomía fundamental entre régimen diurno y nocturno —o sea entre «buia notte» y «chiaro giorno»-, como dice Straparola (2007: 65). Dentro de este antagonismo, Durand (1979: 247-256) considera la noche —contemplativa, mística, fantástica - como símbolo de la inversión. Más recientemente, Ménager (2005) ha estudiado, de manera detallada y en una perspectiva comparada, los significados múltiples y ambiguos de la noche en la literatura del Renacimiento9 . Analiza los tópicos del imaginario nocturno: el contraste entre sol y luna, luz y oscuridad, descanso y vigilia, erotismo y sublimación contemplativa. La noche es a la vez inquietante - como espacio del peligro y del crimen- y propicia — como momento del amor o de la lectura y la reflexión contemplativa-. En lo que respecta al género novelístico que aquí nos interesa, Ménager destaca el hecho que tanto el Decameron como el Heptaméron contienen exclusivamente relatos diurnos — «récits diurnes»—, excluyendo con ello el modelo de las Piacevoli notti. Por otra parte, y refiriéndose a las Sérées de Bouchet, también pone de relieve que la noche es a la vez el momento de la narración y del ensueño, de lo fantástico y de

\footnotetext{
8 Curiosamente, Barella solo cita este soneto, sin tomar en consideración el de Hureta, cuya alusión a Aulo Gelio es menos evidente a primera vista.

9 Véase también Bronfen (2008) y Friese (2011).
} 
la imaginación. De este modo, la noche resulta doblemente predestinada a funcionar como espacio literario.

A partir de estos preliminares quisiéramos analizar las dimensiones significativas - estructurales, retóricas y narrativas - que la noche posee en ambas colecciones de novelas - las Piacevoli notti (1550/1553) de Straparola y las Noches de placer (1631) de Castillo Solórzano ${ }^{10}$ - teniendo en cuenta tanto el marco narrativo como las novelas intercaladas. Con ello, y desde esta perspectiva, nos proponemos asimismo elucidar un aspecto particular de la recepción de la novella italiana en la España de la Contrarreforma, no centrándonos en las cuestiones jurídicas estudiadas por Rabell (2003), sino en el motivo de la noche, muy apreciado también por la pintura barroca, como ilustra el cuadro emblemático de Adam Elsheimer Huida a Egipto (1609) ${ }^{11}$.

\section{LA PRESENTACIÓN DE LA NOCHE EN EL MARCO NARRATIVO}

Ante todo cabe remarcar que las noches en cuestión no son unas noches cualesquiera sino que corresponden a unos momentos clave del calendario eclesiástico: las Navidades y las Carnestolendas. Las Noches de Straparola se desarrollan durante el carnaval, en el contexto de una sociedad cortesana evocada a través de personajes históricos como Ottaviano Maria Sforza, obispo de Lodi, Lucrezia Gonzaga, Antonio y Pietro Bembo, además de numerosas doncellas y dueñas que «il volubile e fugace tempo passavano» con «dolci e dilettevoli intertenimenti» (Straparola 2007: 10). Siguiendo el ejemplo de Straparola, varios literatos españoles también sitúan sus novelas en esta época del año, en la que menudean las tertulias y los saraos, tanto burlescos como festivos. Así lo atestiguan, por ejemplo, Gaspar Lucas Hidalgo con sus Diálogos de apacible entretenimiento (1603); los Desengaños amorosos (1649) de María de Zayas; o el mismo Castillo Solórzano con Tiempo de regocijo y Carnestolendas de Madrid (1633) y su póstuma Sala de recreación (1649). Mientras que Straparola no se refiere al sentido religioso o costumbrista del carnaval, Castillo Solórzano sí explica detenidamente tanto la dimensión teológica como la celebración material de la Navidad, momento en el que data sus Noches de placer:

Llegose la más celebrada y alegre noche de todo el año, en que la segunda persona de la Santísima Trinidad, habiendo tomado carne humana en las entrañas de la Virgen pura, salió della como divino Sol universal, redención nuestra. Esta noche quiso el anciano don Gastón que sus amigos y deudos, con sus mujeres o hijas,

10 Lamentamos no haber podido consultar aun la edición crítica de las Noches de placer en el haber de Giulia Giorgi, de publicación inminente.

11 Para la representación de la noche en la pintura, véanse Borchhardt-Birbaumer (2003) y Ménager (2005: 203-215). 
hiciesen colación en su casa, y prevenido lo necesario, con mucha puntualidad, juntos los convidados, así damas como caballeros, les fue servida una suntuosa colación de gustosas ensaladas, olorosos dulces y exquisitos géneros de frutas que pudo haber en aquel tiempo (Castillo Solórzano 1906: 8).

Con Cristo «como divino Sol universal» (recordando a su antecesor pagano, el «Sol invicto» o Mitra), se revela el sentido metafísico inherente a la antítesis día/noche que domina las Noches, confiriéndoles un claro carácter barroco y contrarreformista, pues lo mundano queda supeditado a lo religioso. Además, en el plano antropológico-cultural, «estas cuatro noches de las fiestas desta Pascua, con las de los días del año [y] Reyes» (Castillo Solórzano 1906: 8), que delimitan el marco temporal de Castillo Solórzano, constituyen un periodo particularmente pernicioso, pues se trata de las doce noches fatídicas «entre los años», cuando los demonios andan sueltos y el orden está suspendido, lo que las asemeja al Carnaval (Shakespeare, The Twelfth Night). En las introducciones y conclusiones a las respectivas noches, repletas de perífrasis cultas, Castillo Solórzano suele destacar el carácter especial de estas noches festivas, ya sea la de Año Nuevo o la de Reyes:

Para más dilatada carrera, descansaba el hermoso desprecio de la ingrata Daphne en el imperio undoso de Neptuno, agasajado de sus hermosas ninfas y nereidas, cuando en el polo ártico dio lugar a que presidiese la noche. Era la primera de aquel año, que por ser el día pasado el festivo de la Circuncisión del Señor, cuando la alegre junta de caballeros y damas quisieron dar principio a un buen año, con el alegría de su entretenimiento, juntos en la casa de don Gastón, y en sus asientos acomodados todos, la música principio de todas estas fiestas (aumentada de nuevas voces o instrumentos) le dio así: [...] (Castillo Solórzano 1906: 339, 394, 438).

Las introducciones a cada una de las noches constituyen momentos culminantes que ponen de relieve la función del marco a la hora de construir el escenario de la sociabilidad nocturna, dando inicio al acto de narrar. Estos párrafos, verdaderos ejercicios de estilo, resultan sumamente significativos para nuestro enfoque, ya que expresan una determinada percepción de la noche, así como su estetización por medio de la retórica. A continuación se tomarán en consideración algunos textos reveladores de ambos autores. Al comienzo de la quinta noche, Straparola evoca la caída de la noche en un tono pastoril que podría parecer convencional si no estableciera un llamativo contraste entre los pastores y la «bella ed onorevole compagnia», ya que mientras los primeros se van a descansar, agotados por el trabajo físico del día, los segundos se reúnen para divertirse:

Il sole, bellezza del ridente cielo, misura del volubil tempo e vero occhio del mondo, da cui la cornuta luna ed ogni stella riceve il suo splendore, oggimai aveva nascosi i rubicondi ed ardenti raggi nelle marine onde, e la fredda figliuola di Latona, 
da risplendenti e chiare stelle intorniata, giá illuminava le folte tenebre della buia notte, ed i pastori, lasciate le spaziose ed ampie campagne e le brinose erbette e le fredde e limpid'acque, si erano con il lor gregge tornati agli suoi usati casamenti, e lassi e stanchi dalle fatiche del giorno sopra i molli e teneri giunchi profondamente dormivano, quando la bella ed onorevole compagnia, posto giú ogni altro pensiero, con frezzoloso passo al concistorio si ridusse (Straparola 2007: 249).

Salta a la vista el rico adorno retórico que caracteriza esta prosa de inspiración clásica, con sus personificaciones mitológicas, sus metáforas y adjetivos haciendo resaltar dos tipos de claridad, más allá del contraste convencional entre luz y sombra. Esta descripción, además de corresponder a los tópicos de la égloga renacentista $^{12}$, permite sacar algunas conclusiones de índole sociocultural respecto a las diferentes funciones que desempeña la noche según las clases sociales —campesinas o urbanas, labradoras o privilegiadas-. Mientras que los unos recuperan las fuerzas físicas, obedeciendo a la «religieuse obligation du repos pour les hommes comme pour les bêtes» ${ }^{13}$, los otros se entregan a un ocio despreocupado, dedicado a diversos pasatiempos, entre ellos el ejercicio intelectual, ya que el «favoleggiare» también se considera como «fatica» (Straparola 2007: 73). Otro cuadro nocturno de tipo pastoril, mucho menos idílico, lo pinta Castillo Solórzano, procediendo a una especie de desdoblamiento antitético de noches, pues en las Noches de placer está enmarcada una 'noche de horror'. Primero, al caer la noche ${ }^{14}$, se abre el acostumbrado escenario del sarao:

Ya había el padre de la luz dado fin a su cotidiano curso en el Ártico polo, para comenzar el del Antártico, y la obscura noche tendía su negro manto sobre la tierra, cuando los caballeros y damas convidados por don Gastón Centellas acudieron a su casa, donde fueron recibidos d'él y sus hermosas hijas, con mucho gusto fueron ocupando una anchurosa sala colgada con ricos paños flamencos; los caballeros tomaron sillas, y las damas almohadas en un dilatado estrado. [...] (Castillo Solórzano 1906: 10).

Bien acomodados en un interior cálido y confortable, los invitados se disponen a escuchar el primer relato, el cual está ambientado, por contraste, en una fría noche de invierno, en las montañas, cuando la naturaleza desencadena sus furores:

Una obscura y tenebrosa noche del encogido y erizado invierno amenazaba con densos nublados y furiosos vientos copiosas plumas, cuando en las faldas de las montañas de Jaca, donde es menos áspera y fragosa la tierra, pues en ella hallaban

\footnotetext{
12 Véase Ménager (2005: 35): «Il y a un soir, il y a un matin. Ceux qui le savent, beaucoup mieux que d'autres, ce sont les bergers de la Renaissance. Il est presque impossible de lire une églogue de cette époque sans trouver le rituel de la nuit qui vient et du retour des troupeaux à l'étable.» 13 Ménager (2005: 35).

14 Respecto al «negro manto de la noche», véase Ménager (2005: 75-77).
}

Edad de Oro, XXXIII (2014), pp. 365-381, ISSN: 0212-0429 
pasto entre sus carrascas y malezas, ligeras y trepadoras cabras de gruesos rebaños que allí había, aumentaban la confusión entre las obscuras sombras ladridos de perros, vigilantes guardas de aquellos ganados, substituyendo entonces las de sus pastores, pues en encerrados apriscos cercanos a bien reparadas chozas les tenían reparándose de la inclemencia de las aguas que prometía el lóbrego seno de la tempestuosa noche (Castillo Solórzano 1906: 13).

Tales evocaciones de la naturaleza, excepcionales en Castillo Solórzano, son la regla en el marco narrativo de Straparola, impregnado por el gusto pastoril del Cinquecento. «[L]a scura notte, adre delle mondane fatiche», lleva el descanso a las criaturas: «gli animali lassi prendevano riposo». Los pájaros se recogen en sus nidos, dejando el imperio del aire a las luciérnagas y a los murciélagos:

I vaghi e occhiuti uccelli avevano giá dato luogo all’oscuritá della notte, e i pipistrelli nemici del sole e a Proserpina dedicati, eran giá usciti delle usate grotte e per lo caliginoso aere lentamente scorrevano, quando l'orrevole e grata compagnia, diposto ogni molesto e affannoso pensiero, allegramente all'usato luogo si ridusse (Straparola 2007: 521, 383, 420).

En Straparola tales evocaciones de la noche constituyen un eje narrativo, pues, según la fórmula estereotipada, contrastan el espacio exterior campestre, sumido en la oscuridad, con el «bel ridotto» urbano de los palacios y sus vastos salones iluminados por hachas níveas que sirven de escenario a las narraciones. Oponen asimismo el sueño de los pastores, del ganado y de la fauna aérea a la alegre velada de la «nobile e orrevol compagnia» que pasa la noche contando y cantando (Straparola 2007: 349). Al amanecer el reino nocturno de Proserpina, «l'onesta e fida compagnia» se reúne en lujosos interiores, bien abrigados del frío y de la humedad de la noche - «Aveva ormai la secca terra mandata fuori l'umida ombra della scura notte» (420)—, fenómenos físicos que poseen determinadas implicaciones médico-humorales nocivas para el hombre.

La estrecha relación con la naturaleza — de acentos pastoriles y mitológicosque se puede observar en Straparola está casi ausente en la obra de Castillo Solórzano, autor más marcadamente urbano, en el plano sociocultural, y barroco, en el plano estético. Este otro enfoque de la noche y de lo nocturno se plasma, por ejemplo, en el tratamiento alegórico del tema, tanto en el marco como en las novelas, tal como ilustra el introito a una de las Noches de placer que plantea la alegoría de "la noche, llevado su funesto carro de los caballos Temor y Sueño" (Castillo Solórzano 1906: 206). En una de las narraciones que corresponden a esta noche, este mismo recurso alegórico se materializa, con motivo de una suntuosa fiesta de bodas, en forma de un carro alegórico que representa la victoria de la aurora sobre 
la noche. Aquí se evidencia la relación de Castillo Solórzano con la cultura festiva de su época, fascinada por las puestas en escena nocturnas ${ }^{15}$ :

Luego que el mantenedor llegó al puesto, por otra parte de la plaza salió un carro conducido por doce caballos blancos; en él iba la Aurora, presidiendo en su principal asiento, que era una hermosa dama; debajo de sus pies, en una grada, iba la noche, con el rostro negro, vestida de la misma color, bordado el vestido de estrellas de oro. Este carro iba con muy acortada música, repartida por las gradas d'él, rodeado de varios instrumentos y sonoras voces; la tarjeta que presentó su padrino a los jueces, era, pintado en campo blanco, un caballero que, en su presencia, tenía a la Aurora y a la noche, con estas letras: «De la noche hice elección; / mas mi suerte se mejora / en dejarla por la Aurora» (Castillo Solórzano 1906: 227).

\section{FUNCIONES NARRATIVAS DE LA NOCHE EN LAS NOVELAS INTERCALADAS}

Si del marco y de la función que la noche desempeña en él pasamos a las novelas propiamente dichas, veremos cómo la noche sirve de escenario a diferentes tipos de acción que ponen de manifiesto la compleja carga semántica de lo nocturno. La noche, oscura y tenebrosa, es el tiempo de la aventura y del peligro, pero también del fingimiento y del engaño. Evidencia el lado oscuro del hombre, lo reprimido, el crimen y la sexualidad, así como lo arcano y la magia. Finalmente, en una especie de mise en abyme, los relatos también reflejan la sociabilidad nocturna desarrollada en la cornice. Estas múltiples implicaciones se articulan de manera distinta en Straparola y Castillo, subrayando los varios cambios históricos que se producen a lo largo de los ochenta años que median entre ambas obras. Así lo pretende probar el análisis comparado de algunos episodios que espigo a continuación.

Una situación narrativa arquetípica que se repite en Straparola (Straparola 2007: 435, 446) es la del viajero perdido en la oscuridad de la noche; al refugiarse bajo un techo cualquiera, allí se encuentra con su destino: la aventura. Tal es el caso, por ejemplo, del «povero fratuncello»:

Il qual, partitosi da Cologna per andare a Ferrara, passò l'Abbadia e il Polesine di Rovigo, ed entrato nel territorio del duca di Ferrara, fu sopragiunto dalla buia notte. E quantunque la luna splendesse, nondimeno per esser giovanetto, solo e in altrui paese, temeva di non esser morto o da masnadieri o da silvestri animali. Non sapendo il poverello dove gire e trovandosi senza pecunia, vidde un certo cortile discosto alquanto dagli altri; ed entratovi dentro senza che da alcuno fosse veduto né sentito, se n'andò al pagliaio, a costo il quale era una scala appoggiata, e salito sopra, meglio che puote per riposare quella notte s'acconciò. Appena il fraticello

15 Véase Ménager (2005: 195-103): «Fêtes de cour»; para la cultura festiva del Siglo de Oro, véase García García / Lobato (2003) y García García / Lobato (2007). 
era coricato per dormire, che sopragiunse uno attilato giovane, il quale aveva nella man destra la spada e nella man sinistra la rotella, e cominciò pianamente cifolare (Straparola 2007: 567).

Semejante punto de partida de la narración es conocido tanto en el folklore como en la Divina commedia, en la Hypnerotomachia Poliphili o en las novelas de caballerías. Si Castillo Solórzano, al contrario que Straparola, no recurre a este esquema es, tal vez, para superar formas tradicionales de impronta medieval, tratándose de un autor cortesano y urbano para el que la relación imaginaria del hombre con la noche ya no constituye un marco de referencia.

En ambos novellieri la noche sintetiza el carácter transgresor de la novela cor$\operatorname{ta}^{16}$, ya se trate de engaños y hurtos, estupros o asesinatos. Pero mientras que los crímenes relatados por Straparola son robos y artimañas más o menos inocentes, Castillo Solórzano relata delitos graves, como asesinatos por celos (Castillo Solórzano 1906: 325) o con diversos venenos (39). Un ejemplo representativo del primer tipo es la historia de la «poavola» (muñeca) que una pareja roba a sus vecinas por medio de una ingeniosa puesta en escena, para enriquecerse gracias a la «gran somma di denari per lei cacata» (274). Pero aparte «il tanto puzzore», la estratagema no resulta provechosa, de modo que marido y mujer quedan defraudados. Straparola combina varios motivos tradicionales y folklóricos - la mujer codiciosa y lista, maquinadora del engaño, una variante de la gallina de los huevos de oro, el estafador estafado - con un sentido del humor que ya provocaba la risa del público medieval y de los lectores de Boccaccio. Evidentemente, este humor carnavalesco, en el sentido bajtiniano del término, ya no corresponde a la mentalidad barroca y contrarreformista, debido, entre otros motivos, a la actividad censora de la Inquisición, según explicara Close (2000 y 2002). En Castillo Solórzano, los crímenes nocturnos - pasionales o políticos- son sanguinarios. Valga como ejemplo la novela octava (noche cuarta), en la que unos conspiradores matan al rey: «Los homicidas tomaron el cuerpo del rey y de su privado, y con la oscuridad de la noche los pusieron a las puertas del real palacio, donde a la mañana fue visto de los que madrugaron aquel funesto espectáculo» (Castillo Solórzano 1906: 311). Al final, los asesinos no escapan a su merecido castigo: «Substanciose la causa, y ya convictos el duque y marqués de ser actores en la muerte del rey y de su gentilhombre de su cámara, fueron condenados a cortarles las cabezas. Esto se hizo secretamente una noche antes del día que el rey tenía señalado para que le jurasen» (318). La noche, momento del crimen y del castigo, construye un campo escópico entre vista y oscuridad, espectáculo y secreto: de noche el cadáver del rey se coloca delante del mismo palacio para quedar expuesto a la vista de todos de madrugada. «Funesto espectáculo» que subraya el carácter del escándalo y la

16 Véase Laspéras (1987: 225-237): «La nouvelle, lieu de transgression». 
trascendencia del regicidio. Por otra parte, el castigo de los conspiradores no se lleva a cabo en un acto público, sino bajo el amparo de la noche, para no afectar a la autoridad monárquica. Asimismo, la presente novela resulta muy reveladora del papel de la violencia en la cultura de la modernidad temprana ${ }^{17}$ y su reflejo literario. En este sentido, el carácter espectacular y atroz de las muertes lleva la impronta de las Historias trágicas, con su celebración estética de la crueldad y la violencia, que pone de manifiesto una relación muy particular con la norma, la ley, el derecho y su transgresión ${ }^{18}$.

La noche como escenario erótico ${ }^{19}$ también se desarrolla de diferente manera en el autor italiano y en el español. En las Piacevoli notti, los placeres de la carne se abordan, según la tradición boccacciana, sin demasiado pudor y en un lenguaje tan crudo que Truchado lo retocó en la traducción española, corrigiendo así la «demasiada libertad de los italianos» ${ }^{20}$. Prolongando la tradición medieval de los fabliaux y otros cuentos licenciosos ${ }^{21}$ basados en el clásico triángulo amoroso, las aventuras eróticas y burlescas de Straparola reconocen el derecho de las mujeres al placer, en particular de las malmaridadas, con las que simpatizan de inmediato los lectores. Un ejemplo ilustrativo en el presente contexto 'nocturno' es el del joven Ippolito, que se hace llevar en un arca a los aposentos de su amada, esposa a su vez del viejo y celoso «messer Erminione». Se las arreglan para convivir de noche, mientras que de día el amante queda escondido en su arca: «Venuto il giorno, il giovane si rinchiuse nell'arca; e la notte se ne usciva fuori a suo piacere, e giaceva con lei» (Straparola 2007: 209).

En Castillo Solórzano, la noche como reino del amor se inunda de tabúes. Aunque «darla música de noche» a su amada (Castillo Solórzano 1906: 346) era una forma convencional de galanteo, tales actividades nocturnas resultan tendencialmente comprometedoras. Incluso para un joven caballero, «[s]alir de casa de noche, estar menos en ella [...] de día» (1906: 131), supone un sospechoso índice de amoríos que alarma al anciano padre. Más embarazosa es la oscuridad para una doncella, expuesta día y noche al ojo vigilante de los demás, siempre dispuestos a poner en entredicho su honestidad. Por ello, se ve obligada a recurrir al secreto y al disfraz:

y yo, por obviar estos inconvenientes, dije a don Luis que me viese menos veces, que se murmuraba en la ciudad que me veía de noche; pero que las que viniese fuese en hábito diferente del que traía porque nadie le pudiese conocer: ofreciose hacerlo así, viniendo algunas noches en traje de segador, con calzones de lienzo,

\footnotetext{
Véase Ruff (2001).

Véase Vaucher Gravili (1982), Pech (2000) y Biet (2006).

Véase Ménager (2005: 39-49): «Nuits d'amour».

Véase González Ramírez (2011).

21 Véase Chevalier (1975: 187-233): «De mujeres y casamientos».
} 
y aquellas antiparas que los que tratan deste ministerio usan (Castillo Solórzano 1906: 50-51).

El hecho de que un padre se entere de que su hija «[da] entrada en casa de noche» a su amante, significa «ver perdido el honesto recato de su casa» y plantear la cuestión de la honra, daga en mano (33-34). A partir de este momento, los acontecimientos dramáticos se agolpan, con la fuga de la joven, un intento de violación y otros elementos truculentos que parecen anticipar las novelas de María de Zayas, denotando, una vez más, la influencia de las Histoires tragiques. Bajo los imperativos de la honra y de una moral contrarreformista, la noche ya no es el momento del goce carnal; se transforma en un ambiente angustioso, obsesionado por las estrategias de ocultación y a menudo antesala de la tragedia.

La noche es, por antonomasia, el reino de las fuerzas ocultas y de la magia, ingrediente muy apreciado de la novela corta ${ }^{22}$. En este sentido, los 'malos saberes ${ }^{23}$ de la «nigromanzia» (410) y la «chiromancia» (423) desempeñan un papel importante en las Piacevoli notti, cuyos personajes creen en la existencia de una «notturna fantasma» (568). Un breve conjuro de Samaritana hace aparecer un suntuoso palacio (164), y el anillo de la princesa Violante se transforma en un «vago giovanetto» (412) con el que ella va a pasar la noche. Los encantamientos maravillosos constituyen el principio operante en los amores de Isabella, llevada por arte de magia de Florencia a Flandes, donde pasa una noche de amor que la deja preñada $(353,357)$. El ritual mágico que da inicio a esta aventura se realiza en la «buia notte»:

Isabella, per la buona risposta tutta allegra, aperse la borsa, e dièle dieci fiorini. Gabrina, per gli ricevuti danari lieta, si mise in vari ragionamenti, aspettando la buia notte. Venuta l'ora destinata dalla maga, ella prese il suo libretto, e fece in terra un cerchio di non molta grandezza, intorniandolo con certi segni e caratteri; indi prese un dilicato liquore e una gocciola ne beve, ed altrettanto ne diede ad Isabella bere (352).

Ante la acción de la censura y la Inquisición, con vistas a extirpar injertos heterodoxos en la literatura de entretenimiento (aunque sí había juego) ${ }^{24}$, no es de extrañar que un solo ejemplo de magia se localice en las Noches de placer. Se trata de la estancia de Ludovico en el palacio de la reina Arminda, bajo el encantamiento del mágico Ardano, donde es servido por damiselas «encubiertas» bajo

\footnotetext{
22 Véanse Teijeiro (2012) y Ruiz Fernández (2012).

23 Véanse las actas del Coloquio Internacional Los malos saberes, organizado por la profesora Folke Gernert, Universidad de Tréveris, 21-22 de noviembre de 2013.

24 Véanse Vega / Weiss / Esteve (2010); Vega / Nakládalová (2012); Vega / Fosalba (2013); y Vega (2013).
} 
una «mascarilla francesa». Cuando, movido por la curiosidad, Ludovico quita la máscara a la durmiente Arminda, provoca un desencantamiento que opera en el sentido del desengaño. De acuerdo con una moral contrarreformista, la linda dama se metamorfosea en una fea repugnante, cual alegoría de la vanidad:

Aquí llegaba cuando Arminda, por haber estado desvelada la noche pasada, y falta de sueño ocupada con varios pensamientos, en orden a su empleo, se adurmió; advirtió en esto Ludovico, y por no dejar pasar la ocasión tan a medida de su deseo, sin dejar la relación que hacía, llegose quietamente a la reina, y desprendiéndola la mascarilla de un lado sin que lo sintiese descubriéndola el rostro, allí obró la fuerza del mágico de Bruneto, de modo que a la vista de Ludovico pareció Arminda la más fea y abominable mujer que hasta allí había visto (Castillo Solórzano 1906: 88).

El tópico humanista de la noche dedicada a la meditación y el estudio ${ }^{25}$ sólo es atestiguado por Straparola, quien lo encarna, sorprendentemente, en un personaje femenino. Casi impensable en la España áurea, fuera del modo irónico, la italiana Costanza se entrega «agli studi delle buone lettere», pasando «las noches leyendo de claro en claro, y los días de turbio en turbio»:

Costanza, essendo pervenuta all'etá di dodeci anni, aveva giá imparato ricamare, cantare, sonare, danzare, e far tutto quello che ad una matrona onestamente si conviene. Ma non contenta di ciò, tutta si diede agli studi delle buone lettere; le quali con tanta dolcezza e diletto abbracciava, che non pur il giorno, ma anche la notte in quelle consumava, afforciandosi sempre di trovar cose che fussero molto isquisite (Straparola 2007: 194).

Para cerrar el círculo cabe mencionar la noche festiva ${ }^{26}$, dedicada a la diversión, al baile y al canto, a los juegos y cuentos, tal como la encontramos en la cornice. A este respecto se observa en las Noches españolas, pero no en las italianas, la ya mencionada mise en abyme, el sarao del marco reflejándose en las justas de algunas novelle, de modo que entre la sociabilidad de primer y de segundo grado apenas hay solución de continuidad. La transición de una a otra va a funcionar precisamente como principio de construcción en la Sala de recreación, donde Castillo Solórzano hace concluir la última novela de cada «noche» con un festejo que se prolonga en los entretenimientos cortesanos del marco.

Al final de este recorrido analítico-comparativo centrado en el motivo de la noche, tan polifacético como revelador, se pueden sacar las siguientes conclusiones. Ante todo, si bien los títulos y la estructura son idénticos, las Piacevoli notti italianas $(1550,1553,1556)$ y las Noches de placer castellanas (1631) se

25 Véase Ménager (2005: 109-150): «La chouette de Minerve».

26 Véase Ménager (2005: 195-202): «Fêtes de cour».

Edad de Oro, XXXIII (2014), pp. 365-381, ISSN: 0212-0429 
distinguen en muchos respectos por lo que se refiere al concepto de la noche y de lo nocturno. De una cultura a otra, y con unos ochenta años de intervalo, que implican la transición del Renacimiento al Barroco, cambia el tratamiento retórico-literario de la noche, así como su carga semántica y axiológica. A pesar de su común fondo cortesano, la evocación de la noche en el marco se transforma de pastoril y 'naturalista' a urbana y alegórica. En las novelas, el lado 'nocturno' del hombre cambia de significado. La tradición medieval, burlesca y carnavalesca que domina en Straparola da paso a una visión más austera, marcada no solo por censura moral de índole contrarreformista, sino también por la tendencia a la problematización y a la seriedad patente desde las Novelas ejemplares (1613). Además se nota en el novelista español un dramatismo narrativo proveniente de las Historias trágicas de Belleforest y Boaistuau, traducidas al castellano a finales de la década de 1580. Asimismo, las diversiones nocturnas van extendiéndose del marco a las novelle, señalando la creciente importancia del ocio urbano.

Recibido: 19/09/2014

Aceptado: 30/10/2014

\section{BIBLIOGRAFÍA CITADA}

Albert, Mechthild (2014). «La autoridad de la antigüedad en la novela corta del Siglo de Oro». En Christoph Strosetzki (ed.), La autoridad de la Antigüedad en el Siglo de Oro. Madrid / Frankfurt am Main: Iberoamericana - Vervuert, pp. 11-28.

- (2013). «Topologías de la sociabilidad en la novela corta del Siglo de Oro». En Eberhard Geisler (ed.), La representación del espacio en la literatura española del Siglo de Oro. Barcelona: Anthropos, pp. 313-334.

- (ed.) (2013). Sociabilidad y literatura en el Siglo de Oro. Madrid / Frankfurt am Main: Iberoamericana - Vervuert.

Barella Vigal, Julia (1985). «Las Noches de Invierno de Antonio de Eslava: entre el folklore y la tradición erudita». Príncipe de Viana, 175, pp. 513-565.

Biet, Christian (ed.) (2006). Théâtre de la cruauté et récits sanglants en France (хvie - хvIIe siècle). París: Robert Laffont (Bouquins).

BorchHardt-Birbaumer, Brigitte (2003). Imago noctis: die Nacht in der Kunst des Abendlandes. Viena: Böhlau.

Bronfen, Elisabeth (2008). Tiefer als der Tag gedacht. Eine Kulturgeschichte der Nacht. Munich: Hanser.

Carvajal, Mariana de (2005). Navidades de Madrid y noches entretenidas. Dámaso Chicharro (ed.). Jaén: Diputación Provincial de Jaén.

Castillo Solórzano, Alonso de (1906). Noches de placer. Emilio Cotarelo y Mori (ed.). Madrid: Librería de la Viuda de Rico.

(1908). Tardes entretenidas en seis novelas. Emilio Cotarelo y Mori (ed.). Madrid: Librería de los Bibliófilos Españoles. 
CAYUEla, Anne (2000). «Tardes entretenidas de Alonso de Castillo Solórzano: el enigma como poética de la claridad», en Actas del XIII Congreso de la Asociación Internacional de Hispanistas: Tomo 1, Medieval, Siglos de Oro. Madrid: Castalia, pp. 449-459.

Chevalier, Maxime (1975). Cuentecillos tradicionales en la España del Siglo de Oro. Madrid: Gredos.

Close, Anthony J. (2000). Cervantes and the Comic Mind of his Age. Cambridge: Cambridge University Press.

(2002). «Lo cómico y la censura en el Siglo de Oro». En María Luisa Lobato y Francisco Domínguez Matito (eds.), Memoria de la palabra. Actas del VI Congreso de la AISO. Madrid / Frankfurt am Main: Iberoamericana - Vervuert, pp. 27-38.

DurAND, Gilbert (1979). Les structures anthropologiques de l'imaginaire. Paris: Bordas.

Eslava, Antonio de (2013). Noches de invierno. Julia Barella Vigal (ed.). Madrid / Frankfurt am Main: Iberoamericana - Vervuert.

FrIESE, Heinz-Gerhard (2011). Die Ästhetik der Nacht: eine Kulturgeschichte. Reinbek: Rowohlt.

García García, Bernardo J., María Luisa Lobato (eds.) (2007). Dramaturgia festiva y cultura nobiliaria en el Siglo de Oro. Madrid / Frankfurt am Main: Iberoamericana - Vervuert.

(eds.) (2003). La fiesta cortesana en la época de los Austrias. Valladolid: Junta de Castilla y León.

García JuRAdo, Francisco (2012). «Aulo Gelio y la literatura española del Siglo xvi: autor, texto, comentario y relectura moderna». Revista de Literatura, 74, 147, pp. 31-64.

GonzÁlez Ramírez, David (2011). «En el origen de la novela corta del Siglo de Oro: Los novellieri en España». Arbor, 187, 752, pp. 1221-1243.

JANIER, André (2006). «Les Sérées» (1584-1597-1598) du libraire-imprimeur Guillaume Bouchet (1514-1594). París: Champion.

JeAnNeret, Michel (1987). Des mets et des mots. París: Corti.

LASPÉRAs, Jean-Michel (1987). La nouvelle en Espagne au Siècle d'Or. Montpellier: Editions du Castillet.

MÉNAGER, Daniel (2005). La Renaissance et la nuit. Ginebra: Droz.

Molina, Tirso de (1996). Los cigarrales de Toledo. Luis Vázquez Fernández (ed.). Madrid: Castalia.

Montero Reguera, José (2006). «El nacimiento de la novela corta en España (la perspectiva de los editores)». Lectura y signo: Revista de literatura, 1, pp. 165-175.

PECH, Thierry (2000). Conter le crime: droit et littérature sous la Contre-Réforme. Les histoires tragiques (1559-1644). París: Honoré Champion.

RABell, Carmen R. (2003). Rewriting the Italian Novella in Counter-Reformation Spain. Woodbridge: Tamesis.

Renaud, Michel (2000). «Un bonhomme de livres: Notes vaguement mimétiques et passablement désinvoltes sur les Serées de Guillaume Bouchet», en Jean-Raymond Fanlo (ed.): «D’une fantastique bigarrure». Le texte composite à la Renaissance. Études offertes à André Tournon. París: Champion, pp. 71-87.

RufF, Julius R. (2001), Violence in Early Modern Europe. Cambridge: Cambridge University Press. 
Ruiz Fernández, María Jesús (2012), «'Ni es cielo ni es açul...’. Teatralidad y magia en los Sucesos y prodigios de Juan Pérez de Montalbán». En Rafael Bonilla Cerezo, José Ramón Trujillo, Begoña Rodríguez (eds.), Novela corta y teatro en el Barroco español (1613-1685). Studia in honorem Prof. Anthony Close. Madrid: Sial Ediciones, pp. 139-154.

Straparola, Giovanni Francesco (2007). Le piacevoli notti, $1^{\text {a }}$ edizione elettronica, e-book realizzato in collaborazione con la Biblioteca dei classici Italiani (http:// www.classicitaliani.it/). Edizione di riferimento: Giovan Francesco Straparola, Le piacevoli notti, a cura Giuseppe Rua, Laterza \& Figli Tipografi-Editori-Librai, 1927.

Teiseiro, Miguel Ángel (2012). «El personaje del nigromante en la novela cortesana». En Rafael Bonilla Cerezo, José Ramón Trujillo, Begoña Rodríguez (eds.), Novela corta y teatro en el Barroco español (1613-1685). Studia in honorem Prof. Anthony Close. Madrid: Sial Ediciones, pp. 37-54.

Vaucher Gravili, Anne de (1982). Loi et Transgression. Les histoires tragiques au xvie siècle. Lecce: Milella.

VEGA, María José (2013). «La ficción ante el censor. La novella y los índices de libros prohibidos en Italia, Portugal y España (1559-1596)». En Valentín Núñez Rivera (ed.), Ficciones en la ficción. Poéticas de la narración inserta. (siglos XV-XVII). Barcelona: Universitat Autònoma de Barcelona. Servei de Publicacions, pp. 49-75.

VEGA, María José, Eugenia Fosalba (eds.) (2013). Textos castigados: la censura literaria en el Siglo de Oro. Berna: Peter Lang.

VeGA, María José, Iveta Nakládalová (eds.) (2012). Lectura y culpa en el siglo XVI / Reading and Guilt in the 16th Century. Barcelona: Universitat Autònoma de Barcelona, Servei de Publicacions.

VEGA, María José, Julian Weiss, Cesc Esteve (eds.) (2010). Reading and Censorship in Early Modern Europe. Barcelona: Universitat Autònoma de Barcelona, Servei de Publicacions. 


\section{(2)}

\section{LAS 'NOCHES': UN SUBGÉNERO NOVELÍSTICO EN PERSPECTIVA COMPARADA}

RESUMEN: El subgénero de las 'Noches', que remonta a las eruditas Noches áticas de Aulo Gelio, se inicia en la Edad Moderna como colección de novelas con las Piacevoli notti de Straparola, traducidas al castellano en 1580/1581, desencadenando una larga serie de obras similares, entre ellas las Noches de invierno (1609), de Antonio de Eslava, y las Noches de placer (1631), de Alonso Castillo Solórzano. En el presente artículo, estas últimas se analizan en comparación con las Piacevoli notti respecto a la descripción y función narrativa de la noche, tanto en el marco entre festivo y pastoril como en las novelas mismas en cuanto escenario del amor y de la magia, del crimen y del engaño. El diferente tratamiento que Straparola y Castillo Solórzano dan a la carga semántica de la noche se explica por la distancia que media entre el Renacimiento italiano y el Barroco español. Palabras Clave: Novela corta, Noche como género, Noche como motivo, Giovanni Francesco Straparola, Alonso de Castillo Solórzano.

\section{The 'Nights': A Comparative Perspective on a Subgenre of the Novella}

ABSTRACT: In the Modern Era, the subgenre 'Noches', that goes back to Aulo Gelio's erudite Noches áticas, emerges with Straparola's collection of novellas, Piacevoli notti, that had been translated into Spanish in 1580/1581. It initiated a large series of similar works, among them Antonio de Eslava's Noches de invierno (1609), and Alonso Castillo Solórzano's Noches de placer (1631). In the current article, the latter will be analyzed in comparison to the Italian Piacevoli notti with respect to the description of the night and its narrative function. There will be a focus on the narrative frame between the festive and the pastoral, as well as on the scenario of love, magic, crime and deception. The different treatment Straparola and Castillo Solórzano give to the semantic load of the night can be explained in terms of the distance between the Italian Renaissance and the Spanish Baroque.

Keywords: Novella, Night as Genre, Night as Theme and Motif, Giovanni Francesco Straparola, Alonso de Castillo Solórzano. 


\section{EDAD DE ORO}

Revista de Filología Hispánica XXXIII

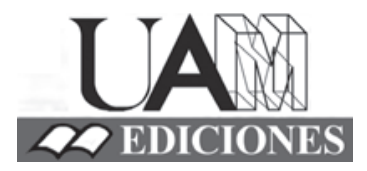




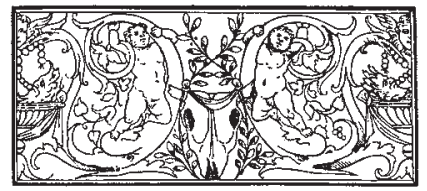

\section{Edad de Oro. Revista de Filología Hispánica}

ISSN: 0212-0429

Dirección:

Teodosio Fernández

Secretaría y edición:

José Ramón Trujillo

Coordinador del volumen XXXIII:

Rafael Bonilla Cerezo

Comité científico internacional:

Carlos Alvar (Univ. de Ginebra)

Ignacio Arellano (Univ. de Navarra)

Javier Blasco (Univ. de Valladolid)

Alberto Blecua (UAB)

Jean Canavaggio (Univ. de París X)

Laura Dolfi (Univ. de Turín)

Aurora Egido (Univ. de Zaragoza)

Víctor García de la Concha (RAE)

Luciano García Lorenzo (CSIC)

Joaquín González Cuenca (Univ. de Castilla-

La Mancha)

Agustín de La Granja (Univ. de Granada)

Begoña López Bueno (Univ. de Sevilla)

Michel Moner (Univ. de Toulouse III)

Joan Oleza (Univ. de Valencia)

Alfonso Rey (Univ. de Santiago)

Lina Rodríguez Cacho (Univ. de Salamanca)

Leonardo Romero Tobar (Univ. de Zaragoza)

Aldo Ruffinatto (Univ. de Turín)

Lía Schwartz (City University of New York)
Redacción y admisión de originales:

Teodosio Fernández

Edad de Oro

Departamento de Filología Española

Universidad Autónoma de Madrid

28049 Madrid (España)

Tfno.: +0034 914974090

correo: teodosio.fernandez@uam.es

Distribución, suscripción y venta:

Servicio de Publicaciones de la UAM

Universidad Autónoma de Madrid

28049 Madrid (España)

Intercambio de publicaciones:

Biblioteca de la Facultad de Filosofía y

Letras (UAM)

Universidad Autónoma de Madrid

28049 Madrid (España)

Han colaborado en este volumen:

Departamento de Filología Española (UAM)

Facultad de Filosofía y Letras (UAM)

Proyecto I+D FFI2013-41264-P La novela

corta del siglo XVII: estudio y edición (y II)

Edad de Oro se recoge en las siguientes bases de datos: SCOPUS, MLA Database, HLAS, Latindex, PIO-Periodical Content Index, ISOC, Dialnet, MIAR, ERIH, DICE, Sumaris CBUC, Ulrich's. Se encuentra evaluada en CIRC: A; INRECH: primer cuartil, posición 6 de 50; MIAR difusión ICDS live: 9.977; SCImago Journal \& Country Rank: H Index 2, SJR 0,101, Q4; RESH índice de impacto: 0.162; ERIH: A INT1; Carhus Plus+: B. 
Evangelina Rodríguez Cuadros (Universitat de València)

Novela cortesana, novela barroca, novela corta: de la incertidumbre al canon 9

Mita Valvassori (Universidad de Los Lagos)

El modelo narrativo del Decamerón en la Edad de Oro: una vieja historia .21

Antonio Gargano (Università degli Studi di Napoli Federico II)

«Difficile est proprie communia dicere»: el género de la novella entre

Boccaccio y Cervantes

Guillermo Carrascón (Università degli Studi di Torino)

Apuntes para un estudio de la presencia de Bandello en la

novela corta del siglo XVII

Leonardo Coppola (Università degli Studi «G. d'Annunzio» di Chieti-Pescara)

La proyección de Straparola en la novela española del Siglo de Oro desde una perspectiva editorial

Mireia Aldomà García

Didactismo, género literario y lector en Giraldi Cinzio

María Jesús Zamora (Universidad Autónoma de Madrid)

«...En tiempo menos discreto que el de agora, aunque de hombres más sabios, se

llamaban a las novelas cuentos». La novela corta y el cuento en el Siglo de Oro......109

Marcial Rubio (Università degli Studi «G. d'Annunzio» di Chieti-Pescara)

La contribución de Cervantes a la novela barroca: la ejemplaridad.

Pierre Darnis (Université Bordeaux Montaigne)

La fuerza de la sangre, La ilustre fregona $y$ Las dos doncellas: ¿tres tipos

folclóricos?

María Soledad Arredondo (Universidad Complutense de Madrid)

De La gitanilla a La sabia Flora malsabidilla. El género, el personaje

y el matrimonio

Antonella Gallo (Università degli Studi di Verona)

Fabulaciones en equívocos burlescos: la Chrónica del monstro imaginado (1615)

de Alonso de Ledesma y novela corta barroca

David González Ramírez (Universidad de Málaga)

El filósofo del aldea (1625) de Baltasar Mateo Velázquez: recepción textual

e hipótesis autorial.

JONATHAN BRADBURY (University of Exeter)

La narrativa breve en la miscelánea del siglo XVII... 
Cristina Castillo Martínez (Universidad de Jaén)

«La fuente del desengaño»: de las Noches de invierno de Eslava a la Tercera

Diana de Tejeda.

MARÍA Zerari (Université Paris-Sorbonne, CLEA)

Furor in fabula: La cruel aragonesa de Castillo Solórzano (o de la dama monstruo).. 241

Giulia Giorgi (Università degli Studi di Ferrara)

Alonso de Castillo Solórzano reescritor de sí mismo: algunas notas sobre los

Escarmientos de amor moralizados y el Lisardo enamorado .257

Angela Fabris (Alpen-Adria-Universität Klagenfurt)

El diálogo con el público y los espacios reales y de maravilla en

Casos prodigiosos y cueva encantada de Juan de Piña 267

María Rocío LePe García (IES San Sebastián, Huelva)

La traducción inglesa de Hipólito y Aminta: una adaptación

con fines comerciales 281

Andrea Bresadola (Università degli Studi di Udine)

La novela española en la Italia del siglo XVII: el caso de Il Feniso

de Francisco de Quintana.

José Teruel (Universidad Autónoma de Madrid)

El triunfo del Desengaño. Marco y desengaño postrero de la Parte segunda

del Sarao y entretenimiento honesto, de María de Zayas

Nieves Romero-Díaz (Mount Holyoke College)

Lecturas alternativas en la Novela del fin bueno en mal principio

de doña Ana Francisca Abarca de Bolea....

Shifra Armon (University of Florida)

Compromiso y distanciamiento en La Venus de Ferrara

de Mariana de Carvajal Saavedra

Mechthild Albert (Rheinische Friedrich-Wilhelms-Universität Bonn)

Las "noches": un subgénero novelístico en perspectiva comparada.... .365

Fernando Copello Jouanchin (Université du Maine, Le Mans)

El mueble en la novela corta del Siglo de Oro: algunas reflexiones

en torno a la cama

Ilaria Resta (Università del Salento):

De la novella al entremés pasando por la novela corta: reescrituras del cuento

La gara delle tre mogli del Cieco di Ferrara. 